\title{
Recognition memory for novel forms following continuous or intermittent tachistoscopic viewing
}

\author{
TERENCE D. CREIGHTON \\ University of Calgary, Calgary, Alberta, Canada T2N $1 N_{4}$
}

\begin{abstract}
Ten adult subjects viewed six novel visual forms presented tachistoscopically such that only one or several visual fixations on the target were possible. Recognition memory for the targets was significantly better when the subject was allowed several fixations, even though the targets were presented for the same total duration. The results were interpreted as supporting Hebb's (1949) theory of perceptual learning.
\end{abstract}

Hebb (1949) proposed that perception of visual forms is learned slowly, depending originally on multiple visual fixations to bring together the separate elements of a pattern into one, representational cell assembly. Studies have shown that infants (Salapatek $\&$ Kessen, 1966; Salapatek, Note 1) and adults (Zusne \& Michels, 1964) scan visual targets as Hebb suggested, and that eye movements increase as the complexity of the stimulus increases (Locher, 1974; Mackworth \& Bruner, 1970; Vitz \& Todd, 1971). There is no direct evidence that these eye movements are necessary for perceptual learning, although Loftus (1972) found a correlation between number of fixations during exposure of stimuli and the subsequent recognition of them. In fact, there are several studies in which recognition scores for complex visual stimuli are unaffected by procedures designed to eliminate eye movements, usually by using exposure times less than $100 \mathrm{msec}$ (e.g., Mooney, 1958, 1960; Rosenblood \& Pulton, 1975).

Several factors could explain such negative results. Most studies use as subjects visually experienced adults. The need for eye movements in such subjects could be reduced by more efficient stimulus sampling strategies (Piaget, 1969; Vurpillot, 1968) and increased abilities of adults to apply self-generated organizational principles to the stimulus array (Freedman \& Haber, 1974). Many studies use as stimuli "vacation slides," which provide many cues for recognition (Rosenblood \& Pulton, 1975; Standing, 1973), or alphanumeric stimuli (Eriksen \& Hoffman, 1963), which are highly overlearned and would easily activate existing cell assemblies (Milner, 1974). Other experimental controls, such as the

This research was supported in part by a R. Samuel McLaughlin Fellowship while the author was at Queen's University. The assistance of Mark Calahan and Dianne Petrachuk is gratefully acknowledged, as are the critical comments of Drs. J. Adam, D. E. Creighton, R. E. Dewar, E. S. Edgington, J. Ells, and G. Rowland. This paper is sponsored by R. E. Dewar, who takes full editorial responsibility for its contents. location of the subject's first fixation, the elimination of afterimages which allow for increased processing time (e.g., Rosenblood \& Pulton, 1975), and the equating of stimulus presentation times across conditions (e.g., Mooney, 1958, 1960), are never employed. The present study is an attempt to investigate recognition memory following brief exposure periods under conditions where the above criticisms do not obtain.

\section{METHOD}

\section{Subjects}

Six male and fouf femaite undergraduates with normal or corrected vision volunteered to participate in this study.

\section{Stimuli}

The exposure stimuli were six 20-turn random shapes (from Munsinger \& Kessen, 1964) chosen randomly and photographed individually on $10.2 \times 15.2 \mathrm{~cm}$ cards with the black shape centered and occupying $3.81 \mathrm{~cm}^{2}$ on the white background. The stimuli were presented tachistoscopically, with the cards $76.2 \mathrm{~cm}$ from the subject, subtending a visual angle of $.051 \mathrm{rad}$ at an intensity of $.137 \mathrm{~cd} / \mathrm{m}^{2}$. The fixation point consisted of a small cross $\left(.64 \mathrm{~cm}^{2}\right)$ in the center of the field illuminated at an intensity of $5.825 \mathrm{~cd} / \mathrm{m}^{2}$. The test stimuli consisted of two booklets of 1020 -turn random shapes, 3 familiar and 7 novel, with the same dimensions as the exposure stimuli.

\section{Apparatus}

Tachistoscopic presentation was conducted in a dark, quiet room, employing a three-field Gerbrands tachistoscope with exposure intervals controlled by a millisecond Hunter timer.

\section{Procedure}

Subjects were tested in a repeated measures design involving two conditions of stimulus presentation, continuous and intermittent, counterbalanced for order. In the continuous presentation condition, subjects viewed binocularly a fixation point (FP) for $40 \mathrm{sec}$, followed by the exposure stimulus (ES) for $2 \mathrm{sec}$, followed by the brighter fixation point, which served as a mask to limit processing time, again for $2 \mathrm{sec}$. A 15-sec rest period followed and the procedure was repeated twice more using different exposure stimuli. In the intermittent presentation condition, subjects viewed the fixation point for $2 \mathrm{sec}$, then the exposure stimulus for $100 \mathrm{msec}$, followed by the fixation point again for $2 \mathrm{sec}$. This series was continued 19 more times (i.e., FP-ES, FP-ES, etc), followed by 
a 15-sec rest period, and the procedure was repeated for two more exposure stimuli. In both conditions, the total trial time was $162 \mathrm{sec}$, the total exposure time for each stimulus was $2 \mathrm{sec}$, and the total exposure time for the fixation point was $3 \times 42 \mathrm{sec}$. Following the last of the three exposure stimuli, subjects were given the booklet of 10 test stimuli and asked to identify the three exposure stimuli. Following a 2-min rest, the entire procedure was then repeated for the subject using the other exposure condition and different stimuli. Instructions to the subjects were descriptive of the procedure and emphasized that they should fixate on the fixation point and refrain from guessing during the recognition test.

\section{RESULTS}

Recognition was significantly better in the continuous presentation $(\mathrm{M}=2.6$ correct recognitions out of $3, \mathrm{SD}=.69$ ) than in the intermittent condition $[\mathrm{M}=1.6, \mathrm{SD}=.84$; $t(9)=3.88, p<.01]$. In both conditions recognition was significantly better than chance $(\mu=.9$, $\sigma=.733 ; \mathrm{z}=3.02, \mathrm{p}<.001)$.

\section{DISCUSSION}

The use of several brief exposures of the stimulus in the intermittent condition creates the possibility of several problems which merit discussion. First, processing time in this condition could have been effectively decreased by para- and metacontrast (Eriksen, 1966) by the brighter fixation point on the exposure stimulus. Sperling (1969) reports approximately a $19 \%$ information loss using a bright pre- and poststimulus mask, but the loss is less if a iuminance mask, rather than a visual noise mask, is used (Spencer, 1969). Most masking studies use very short exposure durations for the target stimulus, making comparisons to the present study difficult. However, an estimate of processing time loss for the 100 -msec stimulus exposure interval would be in the order of $4 \%-8 \%$. This figure is too small to account for all of the differences reported in the present study. The FP mask is long enough to prevent brightness summation of the ES over trials (Erikson \& Greenspoon, 1968), thereby preventing an increase in effective exposure duration. Second, the brief exposures used in the intermittent condition do not affect visual acuity (Keesey, 1960). Third, short-term recognition memory should be better in the intermittent condition than in the continuous condition (Peterson, Hillner \& Saltzman, 1962), implying that the present results were obtained in spite of memory differences across conditions. Fourth, evidence from investigations of the repetition clarity effect (Haber \& Hershenson, 1965) show that 20 brief exposures are sufficient to achieve a high probability of perceiving the stimulus, although one long exposure is slightly more effective than several brief exposures totaling to the same duration. It is doubtful if this slight difference can account for the present results.

Other procedural points should be noted. First, the 100 -msec exposure interval was chosen because it allows for only one fixation (Crovitz \& Daves, 1962). The intent of this condition was to eliminate the possibility of subjects using eye movements to establish representational cell assemblies. Although no monitoring of eye movements was undertaken, instructions to subjects emphasized staring at the fixation point, and such instructions tend to be followed (Smeriglio, Note 2). Second, in the continuous presentation condition, subjects are required to maintain fixation for a prolonged period at a short fixation distance $(76.2 \mathrm{~cm})$. Under these conditions, the eyes will oscillate about a central focus. The likely consequence is that the well-focused exposure time is less than 2 sec. This effest works against the hypothesis. Third, in both exposure conditions, exposure times and time between the end of the exposure procedure and the recognition test were equated.
Fourth, although novel stimuli were employed to reduce the possibility of the subjects using already existing cell assemblies to organize the material, one of the shapes used in the intermittent exposure condition was reported by some subjects as resembling an "upside-down swan," thereby inflating recognition scores for this condition.

The results of the present study suggest that the opportunity for eye movements in the exposure phase of a recognition memory task serves to improve recognition scores. With the novel and complex stimuli used, such eye movements probably serve to produce the contiguous sampling of elements necessary for the formation of elaborate and precise representational cell assemblies (Milner, 1974). It is unlikely in the present study that eye movements were necessary to sample the complete stimulus, as the presentations were foveal. These results are contrary to those reported by Mooney (1958, 1960), who used different exposure and recognition durations. It is possible that the brief exposures used during his recognition task lowered performance in both groups sufficiently to wipe out differences, as he reports $40 \%$ nonrecognitions in both brief- and prolonged-exposure conditions.

Once the cell assembly is established, eye movements may not be necessary for recognition (Franken \& Rowland, 1974), although they may provide useful cues for retrieval (Noton \& Stark, 1971).

\section{REFERENCE NOTES}

1. Salapatek, P. The visual investigation of geometric patterns by the 1-and 2-month-old infant. Paper presented at the meeting of the American Association for the Advancement of Science, Boston, December 1969.

2. Smeriglio, V. L. Prestimulus fixation-point instructions: Are they obeyed and are they influential in determining visual search patterns. Paper presented at the meeting of the Canadian Psychological Association, Quebec City, June 1975.

\section{REFERENCES}

Crovitz, H. F., \& Daves, W. Tendencies to eye movements and perceptual accuracy. Journal of Experimental Psychology, $1962,63,495-498$

ERIKSEN, C. W. Temporal luminance summation effects in backward and forward masking. Perception \& Psychophysics, 1966, 1, 87-92.

Eriksen, C. W., \& Greenspoon, T. S. Binocular summation over time in the perception of form at brief durations. Journal of Experimental Psychology, 1968, 76, 331-336.

ERIKSEN. C. W.. \& HofFman, M. Form recognition at brief durations as a function of adapting field and interval between stimulations. Journal of Experimental Psychology, 1963, 66. $485-499$.

Franken, R. E., \& Rowland, G. L. Visual memory: Accuracy of decisions of familiar-novel for tachistoscopically presented stimuli. Perceptual and Motor Skills, 1974, 38, 1039-1043.

Freedman, J., \& Haber, R. N. One reason why we rarely forget a face. Bulletin of the Psychonomic Society, 1974, 3, 107-109.

HABER, R. N., \& Hershenson, M. The effects of repeated brief exposures on the growth of a percept. Journal of Experimental Psychology, 1965, 69, 40-46.

HEBB, D. O. The organization of behavior. New York: Wiley, 1949.

KeEsEy, U. T. Effects of involuntary eye movements on visual acuity. Journal of the Optical Society of America, 1960, 50, 769-774.

Locher, P. J. Eye-movement parameters and total figure complexity of simple geometric shapes. Perceptual and Motor Skills, 1974, 38, 485-486. 
Loftus. G. R. Eye fixations and recognition memory for pictures. Cognitive Psychology. 1972. 3. 525-551.

Mackworth. N. H.. \& Briner. J. S. Adults and children search and recognize pictures. Human Development. 1970. 13. $149-177$.

Milner. P. M. A model for visual shape recognition. Psychological Revien: 1974. 81. 521-535.

Mooney. C. M. Recognition of novel visual configurations with and without eye movements. Journal of Experimental Psychologi, 1958. 56, 133-138.

Mooney. C. M. Recognition of ambiguous and unambiguous visual configurations with short and longer exposures. British Journal of Psychologi. 1960. 51. 119-125.

Munsinger. H., \& Kessen. W. Uncertainty. structure and preference. Psychological Monographs. 1964, 78, 1-24.

Noton. D.. \& StaRK. L. Scanpaths in eye movements during pattern perception. Science. 1971. 171. 308-311.

Peterson. L. R.. Hillner. K.. \& Saltzman. D. Supplementary report: Time between pairings and short-term recognition. Journal of Experimental Psychology. 1962. 64. $550-551$.

Piaget, J. The mechanisms of perception. London: Routledge \& Kegan Paul. 1969.

Rosenblood. L. K.. \& Pulton. T. W. Recognition after tachistoscopic presentations of complex pictorial stimuli. Canadian Journal of Psychology. 1975. 29. 195-200.
Salapatek. P.. \& Kessen. W. Visual scanning of triangles by the human newborn. Jourrial of Experimental Child Psichology. 1966. 3, 155-167.

SPENCER, T. J. Some effects of different masking stimuli on iconic storage. Journal of Experimental Psychology, 1969, 81. 132-140.

Sperling, G. A model for visual memory tasks. In R. N Haber (Ed.). Information-processing approaches to visual perception. New York: Holt, Rinehart \& Winston, 1969. Pp. 18-31.

Standing. L. Learning 10,000 pictures. Quarterly Journal of Experimental Psychology. 1973, 25, 207-222.

Vitz. P. C.. \& TodD, T. C. A model of the perception of simple geometric figures. Psychological Review, 1971, 78, 207-228.

VURPILlOT, E. The development of scanning strategies and their relation to visual differentiation. Journal of Experimental Child Psychologv, 1968, 6, 632-650.

ZusNe. L., \& Michels. K. M. Nonrepresentational shapes and eyemovements. Perceptual and Motor Skills, 1964, 18. $11-20$. 